\title{
Modelling of cirrus clouds - Part 1b: Structuring cirrus clouds by dynamics
}

\author{
P. Spichtinger ${ }^{1}$ and K. M. Gierens ${ }^{2}$ \\ ${ }^{1}$ Institute for Atmospheric and Climate Science, ETH Zurich, 8092 Zurich, Switzerland \\ ${ }^{2}$ Deutsches Zentrum für Luft- und Raumfahrt, Institut für Physik der Atmosphäre, Oberpfaffenhofen, Germany \\ Received: 16 November 2007 - Published in Atmos. Chem. Phys. Discuss.: 11 January 2008 \\ Revised: 23 October 2008 - Accepted: 1 December 2008 - Published: 28 January 2009
}

\begin{abstract}
A recently developed and validated bulk microphysics scheme for modelling cirrus clouds (Spichtinger and Gierens, 2009), implemented into the anelastic nonhydrostatic model EULAG is used for investigation of the impact of dynamics on the evolution of an arctic cirrostratus. Sensitivity studies are performed, using variation of large-scale updraughts as well as addition of small-scale temperature fluctuations and wind shear. The results show the importance of sedimentation of ice crystals on cloud evolution. Due to non-linear processes like homogeneous nucleation situations can arise where small changes in the outer parameters have large effects on the resulting cloud structure. In-cloud ice supersaturation is a common feature of all our simulations, and we show that dynamics is as least as important for its appearance than is microphysics.
\end{abstract}

\section{Introduction}

Homogeneous freezing of aqueous solution droplets is considered the main pathway to cirrus formation at temperatures below the supercooling limit of pure water droplets (see e.g. Sassen and Dodd, 1988; Heymsfield and Sabin, 1989; Haag et al., 2003). This process needs large ice supersaturation to commence because the foreign solute molecules impede the formation of the ice crystal lattice until they are sufficiently dissolved in water (Koop, 2004). The number of ice crystals that are formed in a nucleation event depends quite sensitively on the cooling rate, which is in turn determined by the vertical wind speed at the moment when the nucleation threshold is reached (Kärcher and Lohmann, 2002; Kärcher and Ström, 2003; Hoyle et al., 2005). Admittedly, box model studies including mesoscale temperature fluctua-

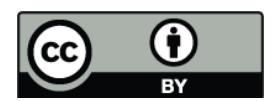

Correspondence to: P. Spichtinger

(peter.spichtinger@env.ethz.ch) tions, like the studies mentioned above, only show a part of the complexity, because of lack of spatial dynamics (in particular sedimentation).

Additionally, the presence of heterogeneous ice nuclei in the same airmass can modify the homogeneous cirrus formation substantially (DeMott et al., 1997; Gierens, 2003; Ren and MacKenzie, 2005; Kärcher et al., 2006; Liu et al., 2007). The dynamical influences on cirrus cloud formation and evolution will be considered in the present paper and the effects of heterogeneous ice nuclei in a subsequent one (Spichtinger and Gierens, 2008, hereafter Part 2). For the simulations we use our newly developed cirrus model (Spichtinger and Gierens, 2009, hereafter Part 1a). We will see that the results offer relatively simple explanations to the issue of longlasting substantial supersaturation found within cirrus clouds (see e.g. Comstock et al., 2004; Lee et al., 2004; Ovarlez et al., 2002; Krämer et al., 2008; Peter et al., 2008, and M. Krämer, personal communication).

The structure of this article is as follows. In Sect. 2 we describe the setup of the simulations and refer to a reference simulation of Part 1a in order to set the stage for the following discussions. Then (Sect. 3) we first analyse the sensitivity of the simulated cirrus formation to small changes in uplift speed. Eventually we add random fluctuations to the velocity field and add wind shear and study their effects. Several aspects of the results are discussed in Sect. 4. We end with a summary and draw conclusions in Sect. 5.

\section{Setup and reference simulation}

We abstain here from a model description. The interested reader will find a detailed description in Part $1 \mathrm{a}$ and a short one in Part 2. However, the setup for the model simulations is described and results from the (quasi) 1-D simulation of an arctic cirrostratus from Part 1a are briefly commemorated

Published by Copernicus Publications on behalf of the European Geosciences Union. 

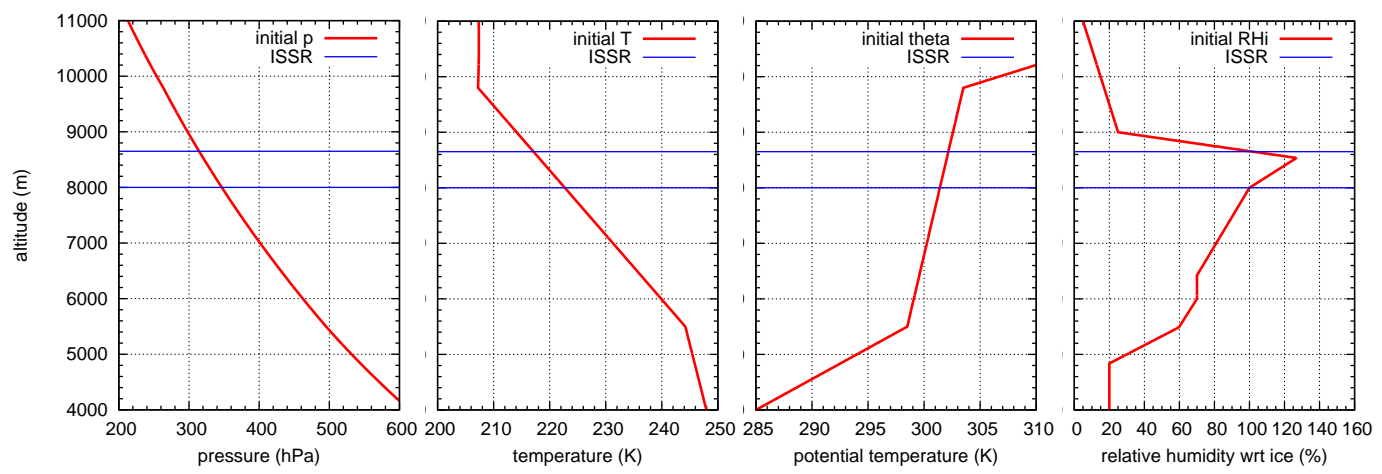

Fig. 1. Initial vertical profiles (pressure, temperature, potential temperature and relative humidity wrt ice) for the simulations of a synoptically driven cirrostratus.

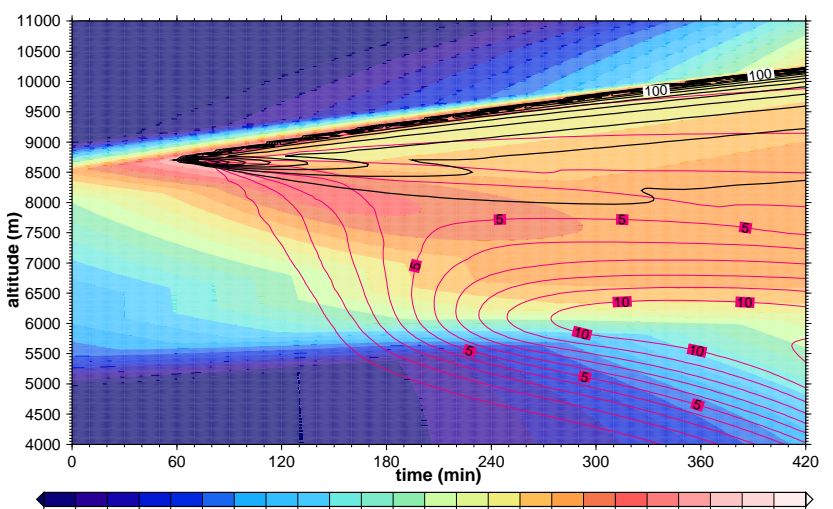

$28 \quad 34 \begin{array}{lllllllllllllll}40 & 52 & 58 & 64 & 70 & 76 & 82 & 88 & 94 & 100106112118124130136142148154160166172\end{array}$ $\mathrm{RHi}(\%)$

Fig. 2. Time evolution of the simulated cirrostratus lifted with a constant vertical velocity of $w=0.05 \mathrm{~m} \mathrm{~s}^{-1}$. The colours indicate relative humidity wrt ice, while lines indicate ice crystal number densities (black, in $\mathrm{L}^{-1}, \Delta n_{c}=10 \mathrm{~L}^{-1}$ ) and ice water content (purple, in $\mathrm{mg} \mathrm{m}^{-3}, \Delta \mathrm{IWC}=1 \mathrm{mg} \mathrm{m}^{-3}$ ).

in order to set the stage for the subsequent sensitivity studies and the 2-D simulations.

We use the following setup for our simulations: The whole 2 -D model domain $(0 \leq x \leq 6.3 \mathrm{~km}, 2 \leq z \leq 11 \mathrm{~km})$ is lifted up adiabatically with a constant updraught velocity of $w=0.05 \mathrm{~m} \mathrm{~s}^{-1}$ as described in Kärcher (2005). This is equivalent to a constant cooling of the background profile $T_{e}$ with a rate of $d T / d t=d T / d z \cdot d z / d t=-g / c_{p} \cdot w=-0.000489 \mathrm{~K} / \mathrm{s}$. The cooling is adiabatic (i.e. $\theta_{e}$ is constant), and is continued for a total simulation time of $t_{s}=7 \mathrm{~h}$. In Fig. 1 the initial profiles for the simulations are shown. The profiles are identical in every vertical column.

We use a horizontal resolution of $\Delta x=100 \mathrm{~m}$ with a horizontal extension of $6.3 \mathrm{~km}$, cyclic boundary conditions in $x$ direction, a vertical resolution of $\Delta z=10 \mathrm{~m}$ and a dynamical time step of $\Delta t=1 \mathrm{~s}$. Because of the small vertical velocity there is no need of a time splitting for the microphysics

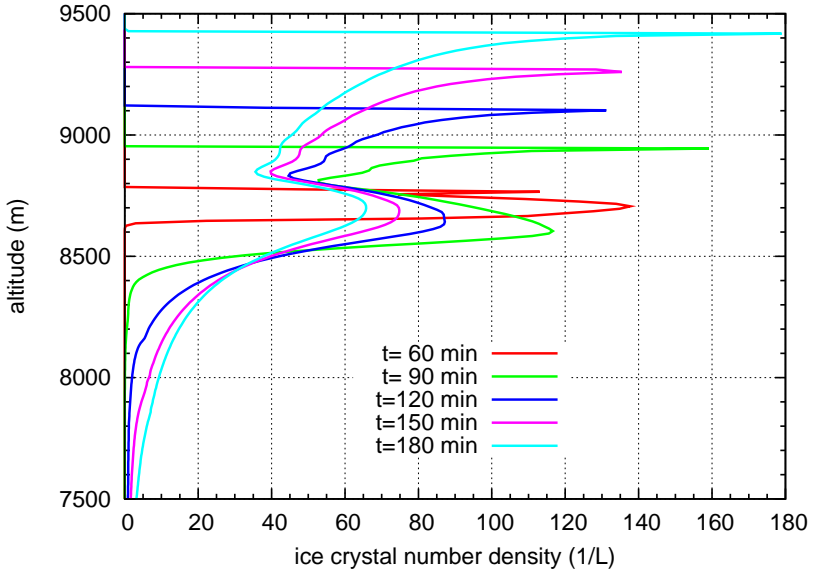

Fig. 3. Profiles of ice crystal number densities at various simulation times in the simulation with constant uplift of $w=0.06 \mathrm{~m} \mathrm{~s}^{-1}$. The peak is much more pronounced as in the reference case ( $w=0.05 \mathrm{~m} \mathrm{~s}^{-1}$, see Part 1a, Fig. 17) due to higher ice crystal densities due to the stronger updraught. Note how the position of the first nucleation peak shifts to lower altitudes relative to the nucleation layer in the upper part of the cloud with time.

scheme. For the background aerosol $\left(\mathrm{H}_{2} \mathrm{SO}_{4}\right)$ we use a number density of $n_{a}=N_{a} \rho=300 \mathrm{~cm}^{-3}$ with geometric standard deviation $\sigma_{r}=1.4$ and geometric mean radius of $r_{m}=25 \mathrm{~nm}$ for the lognormal distribution.

In Fig. 2 the temporal evolution of relative humidity wrt ice, and ice crystal mass and number concentrations, resp., are shown (this is Fig. 17 of Part 1a).

As described in Part 1a, the first nucleation event occurs at $t \approx 60$ min. The supersaturation peak of about $154 \%$ RHi triggers homogeneous nucleation. Within a few minutes a large amount of ice crystals $\left(N_{c} \rho \sim 100 \mathrm{~L}^{-1}\right)$ is formed. Because of the high supersaturation the ice crystals can grow quickly and deplete a fraction of the water vapour, which reduces the relative humidity. Ice crystals grow and soon start to fall. 


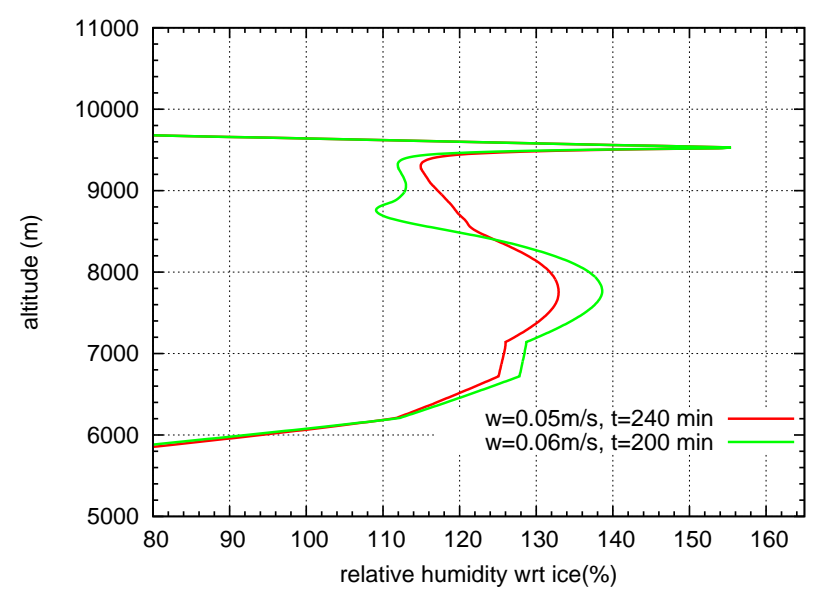

Fig. 4. Vertical RHi-profiles for the simulations at the same altitude, i.e. at equivalent times: $t\left(w=0.05 \mathrm{~m} \mathrm{~s}^{-1}\right)=240 \mathrm{~min}$ and $t\left(w=0.06 \mathrm{~m} \mathrm{~s}^{-1}\right)=200 \mathrm{~min}$, respectively.

Therefore the peak of high supersaturation at the top of the ISSR is influenced very weakly by the depletion of the water vapour. The peak is permanently maintained for the whole simulation time and is a permanent source for homogeneous nucleation at the top of the ISSR.

The combination of crystal growth and sedimentation causes two effects: On the one hand, the supersaturation is reduced by crystal growth such that the relative humidity cannot reach the threshold for homogeneous nucleation in the lower part of the cloud. This effect might be dubbed "sedimentation induced quenching of nucleation".

On the other hand, the falling ice crystals formed at the top of the cloud are the only sink for the water vapour. Although the continuous homogeneous nucleation events permanently form new ice crystals, these are spread vertically over the whole cloud depth resulting in relatively low number densities. Thus, inside the cloud, ice supersaturation is maintained. Sedimentation obviously plays a crucial role for the development and the structure of the simulated cirrus cloud and for the maintenance of supersaturation within the cloud.

The nucleation event at $t \sim 60 \mathrm{~min}$ forms a large number of ice crystals, resulting in a downward moving peak of high ice crystal number densities. In agreement with former studies by Lin et al. (2005); Kärcher (2005) ice supersaturation inside the cirrus is found and maintained by the sedimenting ice crystals depleting the gas phase water vapour such that no homogeneous nucleation can take place within the cirrus.

\section{Studies of dynamical effects}

In this section we study the sensitivity of properties of cirrus clouds formed by homogeneous freezing on dynamics. First we consider how cloud properties change with varying vertical wind, which is the large-scale component of the dy-

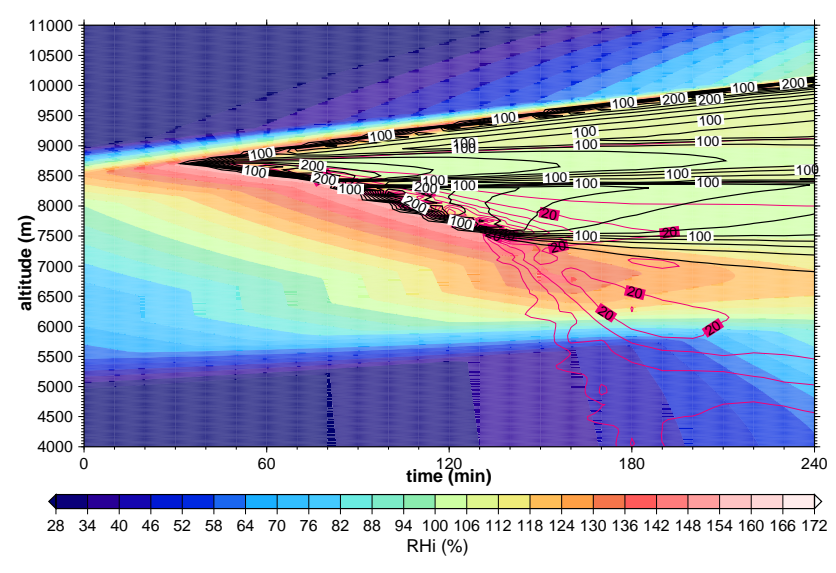

Fig. 5. Time evolution of the simulated cirrostratus lifted with a constant vertical velocity of $w=0.08 \mathrm{~m} \mathrm{~s}^{-1}$. The colours indicate relative humidity wrt ice, while lines indicate ice crystal number densities (black, in $\mathrm{L}^{-1}, \Delta n_{c}=20 \mathrm{~L}^{-1}$ ) and ice water content (purple, in $\mathrm{mg} \mathrm{m}^{-3}, \Delta \mathrm{IWC}=5 \mathrm{mg} \mathrm{m}^{-3}$ ).

namics. Then we introduce temperature fluctuations that lead to small eddies and thus represent small-scale dynamics. Finally we add wind shear, again a large-scale component of the dynamics.

\subsection{Variation of updraught velocities}

First, we test the sensitivity of the simulation results shown in Part 1a and commemorated in the previous section to variations in the updraught velocity. We choose a set of values in the synoptic range, $w=0.06 / 0.08 / 0.1 \mathrm{~m} \mathrm{~s}^{-1}$. In order to avoid that supersaturation is reached below our usual cloud layer we use shorter simulation periods than above, namely $t_{s}=6 \mathrm{~h}$ for $w=0.06 \mathrm{~m} \mathrm{~s}^{-1}$ and of $t_{s}=4 \mathrm{~h}$ for $w=0.08 / 0.1 \mathrm{~m} \mathrm{~s}^{-1}$, respectively.

For the simulation with $w=0.06 \mathrm{~m} \mathrm{~s}^{-1}$ the structure of the developing cirrus is quite similar to the reference simulation with $w=0.05 \mathrm{~m} \mathrm{~s}^{-1}$ described in Sect. 2 (and in Part 1a). However, in spite of the small increase in $w$, several differences begin to appear. Since the number of ice crystals that form in a homogeneous nucleation event increases with updraught speed (roughly $\propto w^{3 / 2}$ ) the peaks in the profiles of $n_{c}=N_{c} \rho$ and $q_{c}$ are much more pronounced in this simulation than in the former one. The profiles are shown in Fig. 3.

Because of the larger crystal number concentration the water vapour is depleted more efficiently than before, in particular where $n_{c}$ peaks. The increased $n_{c}$ implies more competition for the available water vapour, on average smaller crystals and reduced terminal velocities. Thus it takes longer to seed the lower part of the ISSR layer with ice crystals and supersaturation can increase there to higher degrees than in the former simulation. Fig. 4 shows the vertical relative humidity profiles at equivalent time steps, $t\left(w=0.05 \mathrm{~m} \mathrm{~s}^{-1}\right)=240 \mathrm{~min}$ and $t\left(w=0.06 \mathrm{~m} \mathrm{~s}^{-1}\right)=200 \mathrm{~min}$, respectively. 


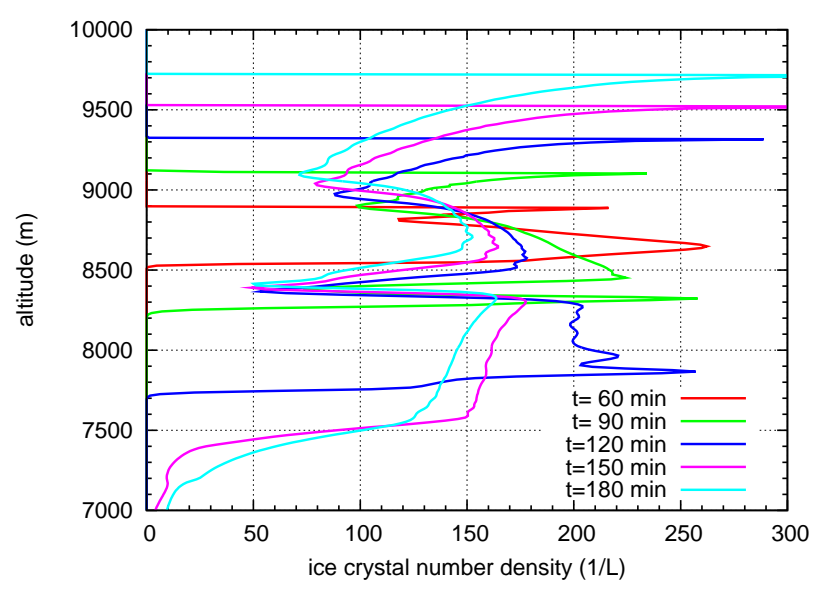

Fig. 6. Ice crystal number densities for $w=0.08 \mathrm{~m} \mathrm{~s}^{-1}$ at different simulation times. For the early simulation times, the moving peak is visible, while for $t=90 / 120 \mathrm{~min}$, the in-cloud nucleation event in the vertical range $7700 \leq z \leq 8400 \mathrm{~m}$ appears. The ice crystals, formed in the secondary nucleation event are then dispersed over the lower part of the cloud $(t=150 / 180 \mathrm{~m})$. This leads to a layer structure of the cirrus cloud.

In both simulations enough ice crystals are eventually sedimented over the whole depth such that further nucleation events inside the supersaturated layer are prevented.

By increasing the vertical velocity further to $w=0.08 \mathrm{~m} \mathrm{~s}^{-1}$, the quality of the results dramatically changes, as the evolution of the variables RHi, $n_{c}$ and IWC shown in Fig. 5 makes evident:

The first nucleation event takes place at $t \approx 40 \mathrm{~min}$, producing $n_{c} \sim 230 \mathrm{~L}^{-1}$ of ice crystals. Now, the chain of events that we just have sketched reappears, but with enhanced intensity: More crystals imply stronger competition for available vapour, lower growth rates and reduced fall speeds. In this case the sedimentation time scale is longer than the cooling time scale in the lower part of the supersaturated layer, such that the threshold for homogeneous nucleation is reached there, i.e. the sedimenting ice crystals are not able to reduce the supersaturation efficiently. New crystal production starts thus lower in the ISSR, forming new peaks in the $n_{c}$ profiles, as shown in Fig. 6:

The new peaks and the peak from the first nucleation event are vertically separated such that the cloud obtains a layered structure, clearly different from the cases with slower uplift. Further nucleation events can occur within the ISSR until eventually ice production (nucleation and growth) and sedimentation have filled the cloud everywhere with enough ice crystals such that further cooling is no longer able to drive the relative humidity above the nucleation threshold. Instead, the relative humidity is reduced inside the cirrus cloud close to ice saturation. Still further increase of $w$ to $w=0.1 \mathrm{~m} \mathrm{~s}^{-1}$ does not lead to further structural changes, yet even more ice crystals are produced in the primary and secondary nucleation events, and supersaturation is eventually reduced close to saturation very effectively. In Fig. 7 vertical profiles of relative humidity for the set of simulations at times $t\left(w=0.05 \mathrm{~m} \mathrm{~s}^{-1}\right)=240 \mathrm{~min}$, $t\left(w=0.06 \mathrm{~m} \mathrm{~s}^{-1}\right)=200 \mathrm{~min}, t\left(w=0.08 \mathrm{~m} \mathrm{~s}^{-1}\right)=150 \mathrm{~min}$ and $t\left(w=0.10 \mathrm{~m} \mathrm{~s}^{-1}\right)=120 \mathrm{~min}$, respectively, are shown; this impressively demonstrates how slight changes in the vertical velocity can lead to completely different cloud structures. This non-linear behaviour is, of course, a consequence of the non-linear behaviour of the nucleation process of which one could say it has only two states: on or off. This is because of the short duration of a typical nucleation event (in order of tens of seconds).

\subsection{Effect of small-scale fluctuations and 2-D structure}

So far the simulations were run without superposed fluctuations, such that there was no horizontal variability in the model (which made the simulations effectively 1-D). This is useful for process studies, for representing the qualitative structure of the formed cirrus clouds. Now we are going to make the simulations more realistic by inclusion of fluctuations of temperature (i.e. perturbation of the wind fields) and wind shear into 2-D simulations with EULAG. Temperature fluctuations on scales of the order hundred kilometres in the upper troposphere are of the order $1 \mathrm{~K}$ (Gierens et al., 2007), on the cloud resolving scale we expect smaller variations (see also Bacmeister et al., 1999). The fluctuations are generated by superposition of uncorrelated Gaussian perturbations with a standard deviation of $\sigma_{T}=0.1 \mathrm{~K}$ onto the background temperature field in the initialisation. This induces additional fluctuations in the horizontal and vertical wind field (i.e. small eddies).

The resulting perturbations of the vertical wind, $w^{\prime}$, at simulation time $t=60 \mathrm{~min}$ are shown in Fig. 8.

We find for the case with background vertical wind $w=0.05 \mathrm{~m} \mathrm{~s}^{-1}$ that the perturbations reach the same order of magnitude as the prescribed large scale updraught. Anyway, the resulting wind speeds are sufficiently small to allow a fixed time step of $d t=1 \mathrm{~s} \mathrm{(cf.} \mathrm{Part} \mathrm{1a).}$

Although the initial temperature perturbations are uncorrelated, the wind field develops coherent structures, small eddies of sizes of few hundred metres which remain persistent throughout the simulation. Nevertheless, the turbulent kinetic energy decreases with time. For illustration we show in Fig. 9 the evolution of the distribution for the component $w^{\prime}$.

The persistence of the eddies is a consequence of the stable initial background temperature profiles. Below $z=5500 \mathrm{~m}$ and above $z=9800 \mathrm{~m}$ (below and above the ISSR) the stability is strong, quantifiable by a Brunt-Vaisala frequency in the range $0.0172 \leq N \leq 0.0182 \mathrm{~s}^{-1}$ (below) and in the range $0.0219 \leq N \leq 0.0226 \mathrm{~s}^{-1}$, representing stratospheric air (above). For comparison, a typical value of the BruntVaisala frequency in the upper troposphere is $N \sim 0.01 \mathrm{~s}^{-1}$ 


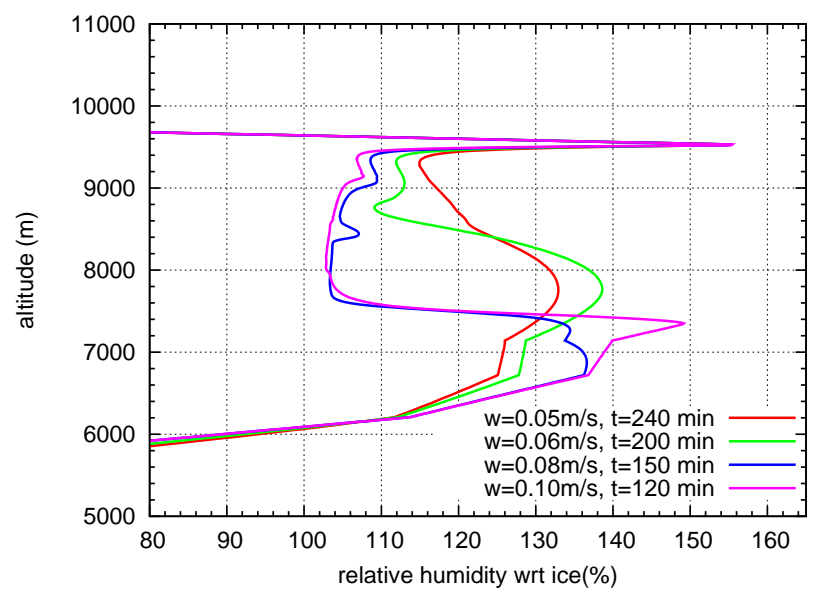

Fig. 7. Vertical RHi profile at the same altitude, i.e. at equivalent simulation times for all four simulations with different vertical updraught $\left(w=0.05 / 0.06 / 0.08 / 0.1 \mathrm{~m} \mathrm{~s}^{-1}\right)$.

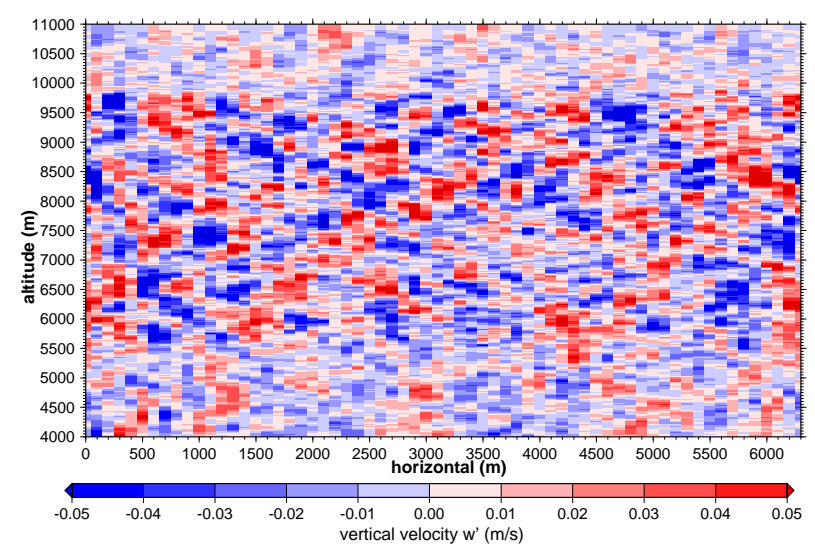

Fig. 8. Vertical velocity perturbation $w^{\prime}$ at simulation time $t=60 \mathrm{~min}$ for a prescribed updraught of $\bar{w}=0.05 \mathrm{~m} \mathrm{~s}^{-1}$.

and in the lowermost stratosphere is $N \sim 0.02-0.03 \mathrm{~s}^{-1}$, respectively (Birner, 2006). The ISSR layer is only slightly stable $\left(N=0.006 \mathrm{~s}^{-1}\right)$, and indeed the initial temperature fluctuations can occasionally and locally cause neutral and unstable stratification.

In Fig. 10 the vertical profiles of ice crystal number density, ice water content and relative humidity for a background vertical velocity of $w=0.05 \mathrm{~m} \mathrm{~s}^{-1}$ are presented for simulation times $t=120 / 180 \mathrm{~min}$, respectively. By and large the mean profiles are similar in shape to those of the 1-D simulations, but the panels show also that temperature and wind fluctuations have a considerable effect on the results when looked at in more detail.

Effects concerning ice crystal number densities are mainly due to fluctuations in the vertical wind, which is clear from the sensitivity studies above and idealised box model calculations in Part 1a. In some regions the vertical wind is higher

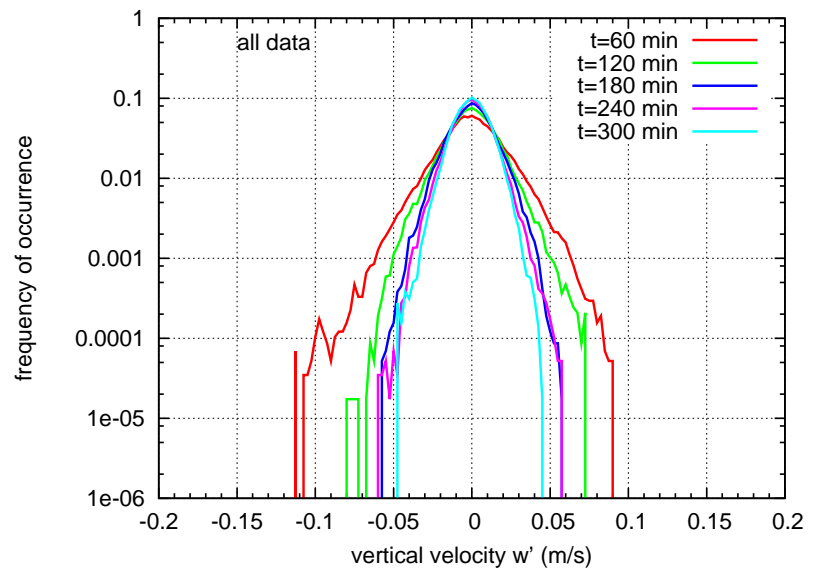

Fig. 9. Evolution of the vertical velocity perturbation distribution for an constant updraught of $w=0.05 \mathrm{~m} \mathrm{~s}^{-1}$ over a simulation time of $60 \leq t \leq 300 \mathrm{~s}$.

than normal, i.e. than the prescribed large scale updraught, hence more ice crystals are produced there. In other regions the vertical wind is reduced or even negative, so less than normal or no crystals are produced there. The effect on the humidity field is complex: In regions with higher $w$ more ice crystals can consume more water, but also the cooling time scale gets shorter, i.e. the saturation vapour pressure is reduced more quickly. In regions with reduced or even negative $w$ it is vice versa. Because of the full 2-D dynamics, the temperature fluctuations do not only affect the vertical velocity field but also introduce small scale circulations, i.e. horizontal motion, which can advect the ice crystals and thus mix ice from high- and low- $w$ regions.

In places where higher than average crystal numbers are produced by chance stronger vertical updraughts, the crystals remain small and obtain low fall speeds. Hence they are predominantly transported horizontally by the eddies. In places, however, where less than average number densities are produced (due to chance weaker uplift, or even downward motion), crystals grow faster and obtain higher fallspeeds. These crystals reach the lower parts of the ISSR and reduce the ice supersaturation there. These sedimenting crystals can thus inhibit homogeneous nucleation further down in the ISSR, an effect one might term "sedimentation induced quenching of nucleation".

The sedimentation induced quenching of nucleation that occurs here as a simple consequence of the small-scale turbulent motions, has important consequences for the cloud evolution. This becomes obvious in the profiles of Fig. 10. The profiles of the 1-D simulations (i.e. no fluctuations) are close to the maxima ( $n_{c}$ and IWC) and minima (RHi) of the ranges shown. Hence, additional fluctuations have the tendency to reduce the mean values of cloud ice and crystal number concentrations and to leave more water in the vapour phase, that is, considerable in-cloud supersaturation is maintained for a longer while. 

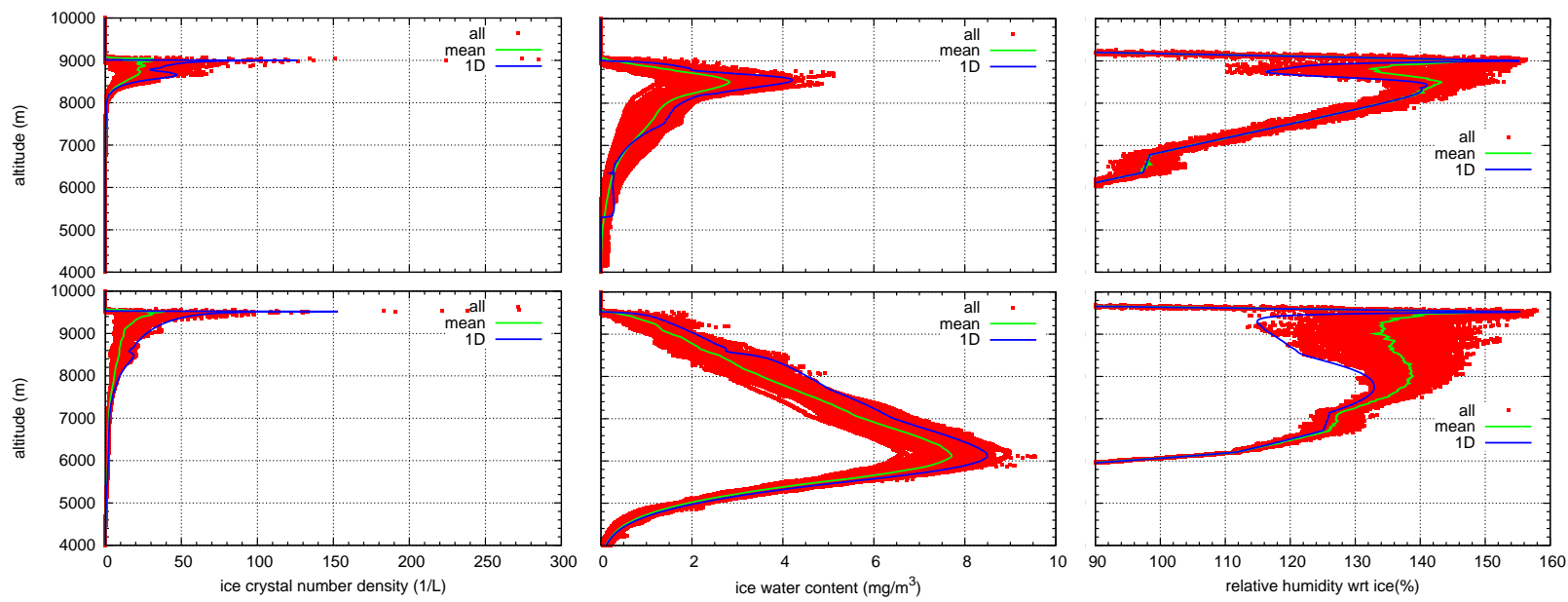

Fig. 10. Ice crystal number density (left), ice water content (middle) and relative humidity wrt ice (right) at $t=120 \mathrm{~min}$ (top panel) and at $t=240 \mathrm{~min}$ (bottom panel) for a constant updraught of $w=0.05 \mathrm{~m} \mathrm{~s}^{-1}$ and additional temperature fluctuations. The values at all grid points are indicated by the red dots, the mean value is represented by the green line and the blue line indicates the values of the corresponding 1-D simulation.

Figure 11 shows the ice number density profiles for a case with a slightly stronger updraught, viz. $w=0.08 \mathrm{~m} \mathrm{~s}^{-1}$. We see that the quenching of nucleation reaches far down in the ISSR, and almost no ice crystals are present in the zone around $8000 \mathrm{~m}$ altitude where the simulation that neglects fluctuations shows more than $200 \mathrm{~L}^{-1}$ (cf. Fig. 6). The 2-D humidity field at $t=120 \mathrm{~min}$ for this case is shown in Fig. 12. The left part of that figure shows the corresponding humidity profile for the 1-D simulation using the same colour code. The most clear differences appear (at that stage of the cloud evolution) in the upper part of the cloud, where instead of a relaxed humidity field (i.e. saturation, green) we find ice saturated spots intermixed into a supersaturated (RHi exceeding 130\%) background. The rhs panel of that figure shows ice number density maxima (black contours) located exactly in the saturated spots, whereas IWC (purple contours) is distributed much more evenly, because this is controlled by the available water vapour. The cloud in the 2-D simulation reaches far further down than the 1-D cloud, because less but heavier ice crystals are produced that obtain higher fall speeds.

One might conclude that the previously shown layered cloud structure (cf. Fig. 11) is only a 1-D artifact. However, this is not true: When the prescribed vertical velocity is enhanced again to $w=0.1 \mathrm{~m} \mathrm{~s}^{-1}$ the in-cloud nucleation events (which cause the layered structure) reappear, although slightly weaker than in the 1-D case. Of course, the basic random mechanism of having spots with lower than average nucleation rate, causing less but faster falling crystals, is still in effect. However, this time nucleation is not quenched in the middle and lower parts of the cloud because the falling crystals come too late. Before they arrive from above, the cooling
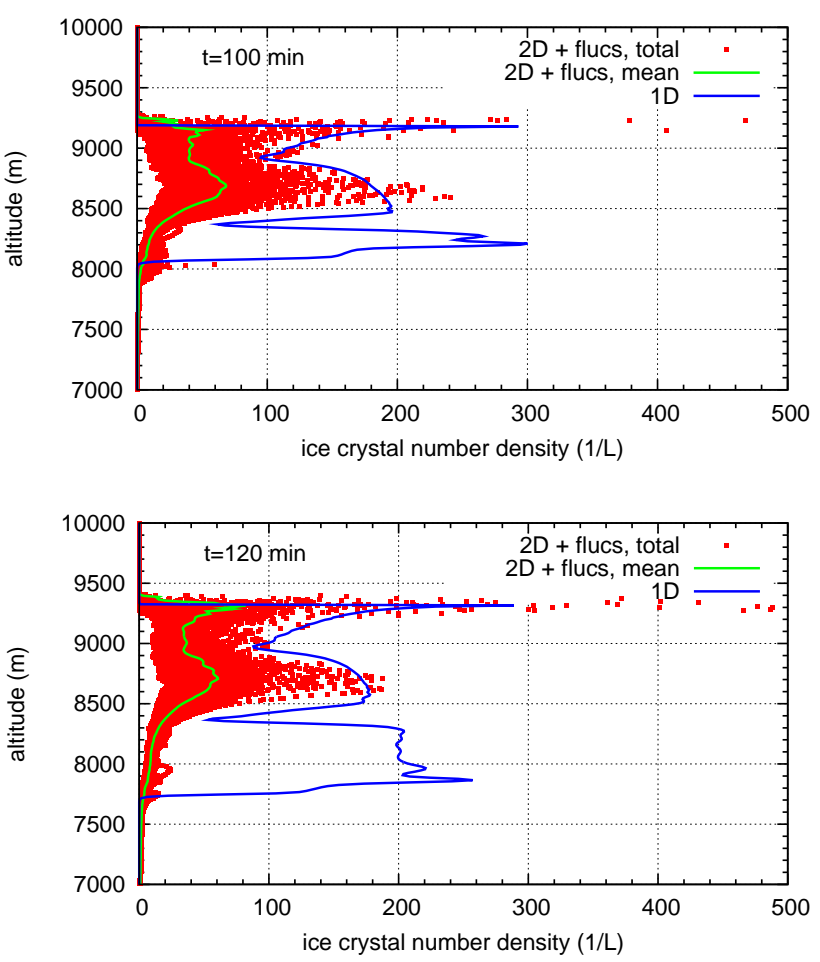

Fig. 11. Ice crystal number densities for a vertical updraught of $w=0.08 \mathrm{~m} \mathrm{~s}^{-1}$ with fluctuations (red dots: all grid points, green line: mean value) and in the corresponding 1-D simulation (blue line) for $t=100 \mathrm{~min}$ (top) and $120 \mathrm{~min}$ (bottom), respectively. In the simulation including fluctuations the inside cloud nucleation events are missing at the bottom of the cloud, compared to the 1-D case. 

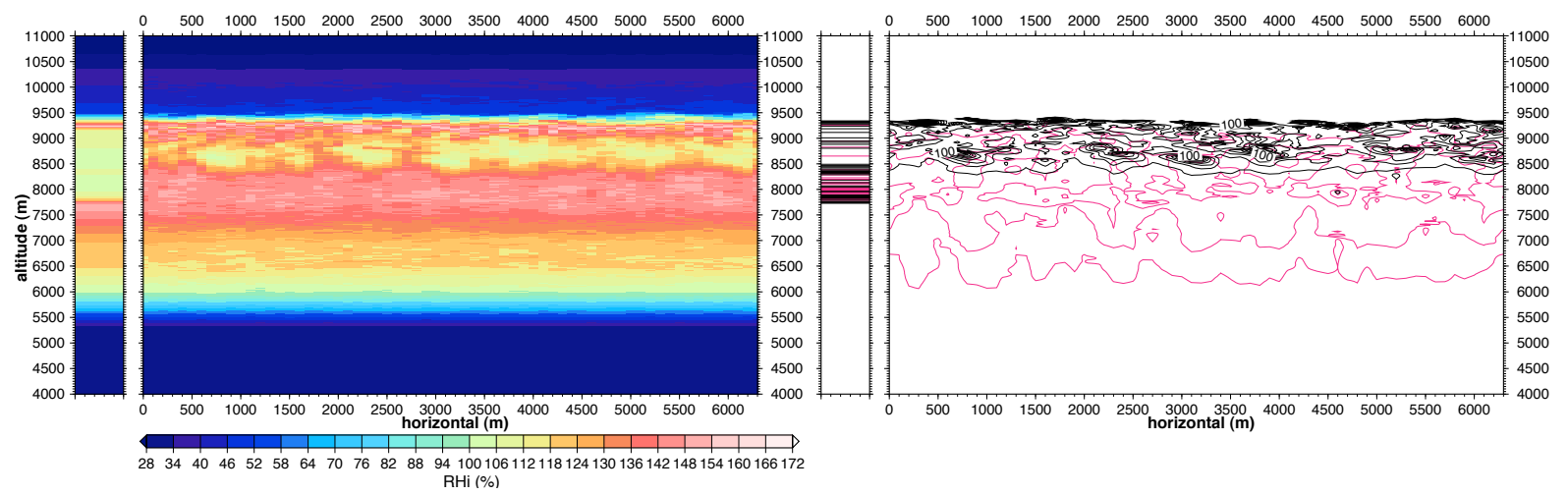

Fig. 12. 2-D structure of relative humidity wrt ice (left panel) and ice water content/ice crystal number concentration (right panel) for simulations with constant updraught of $w=0.08 \mathrm{~m} \mathrm{~s}^{-1}$ at simulation time $t=120 \mathrm{~min}$. Isolines of IWC and $n_{c}$ are indicated by black and purple, respectively. Additionally, the values for the corresponding "1-D" simulations are shown in the small diagram left to the full 2 -D panels.

has already driven the supersaturation over the threshold for homogeneous nucleation; hence in-cloud nucleation reappears. This stresses the point that dynamics is similarly important as microphysics in terms of structuring cirrus clouds and it is noteworthy to observe that even small scale dynamics and small changes in the background dynamics can completely change the vertical structures of cirrus clouds, by disturbing the fragile balance of the processes growth, cooling and sedimentation.

\subsection{Effects of wind shear}

Now we add horizontal wind shear of $d u / d z=10^{-3} \mathrm{~s}^{-1}$, i.e. we start with $u(z=2 \mathrm{~km})=0 \mathrm{~m} \mathrm{~s}^{-1}$ and end up with $u(z=11 \mathrm{~km})=9 \mathrm{~m} \mathrm{~s}^{-1}$. The chosen shear value is weak, but in the range of what is observed in the upper troposphere (see, e.g., the statistics presented by Dürbeck and Gerz, 1996; Birner, 2006).

Although the shear is weak it has a big effect on the cloud structure as seen when comparing Fig. 8 to Fig. 13 which show the perturbation of the vertical wind. Evidently, shear induces larger coherent structures in the turbulent wind field, which is a well-known effect (e.g. Gerz, 1991). The effect can be explained by the superposition of the vorticity from the random motions with the vorticity induced by the shear. The superposition enhances one vorticity direction and weakens or even cancels the opposite, which yields a rectification of the vortices. Superposition of rectified vortices yields larger vortices, that is, the coherent structures that we see. The figure shows also that the amplitudes of the wind perturbations are smaller in the sheared case than in the nonsheared one. This is probably due to conservation of kinetic energy which is redistributed from the small eddies to the coherent structures when shear is switched on.

The changed dynamics has an effect on the microphysical evolution in the following way. First, the coherent structures

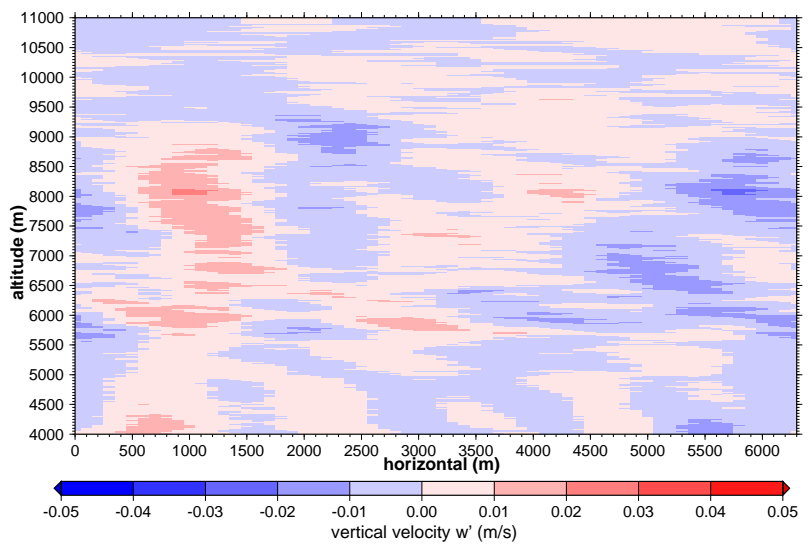

Fig. 13. Vertical velocity perturbation $w^{\prime}$ at simulation time $t=60 \mathrm{~min}$ for a case with large-scale updraught of $w=0.05 \mathrm{~m} \mathrm{~s}^{-1}$ and wind shear of $10^{-3} \mathrm{~s}^{-1}$.

can be expected to enhance horizontal mixing, and second, the smaller amplitudes of $w^{\prime}$ leave less spots than before in the ISSR with strongly reduced ice formation. Hence sedimentation induced quenching of nucleation is expected to be weaker in a shear than in a no-shear case. The effects of these changes can indeed be seen in the simulations.

In Fig. 14 the vertical profiles of ice crystal number density, ice water content and relative humidity for the 1-D simulation and the 2-D simulation with horizontal wind shear are shown for simulation times $t=120 \mathrm{~min}$ and $t=240 \mathrm{~min}$. It can be seen clearly that the wind shear dampens in combination with the high thermal stability the vertical velocity fluctuations generated by the initial temperature fluctuations. Therefore the results of this series are between those of the 1-D simulations and the 2-D simulations without wind shear. In fact, in case of wind shear for the simulation with 

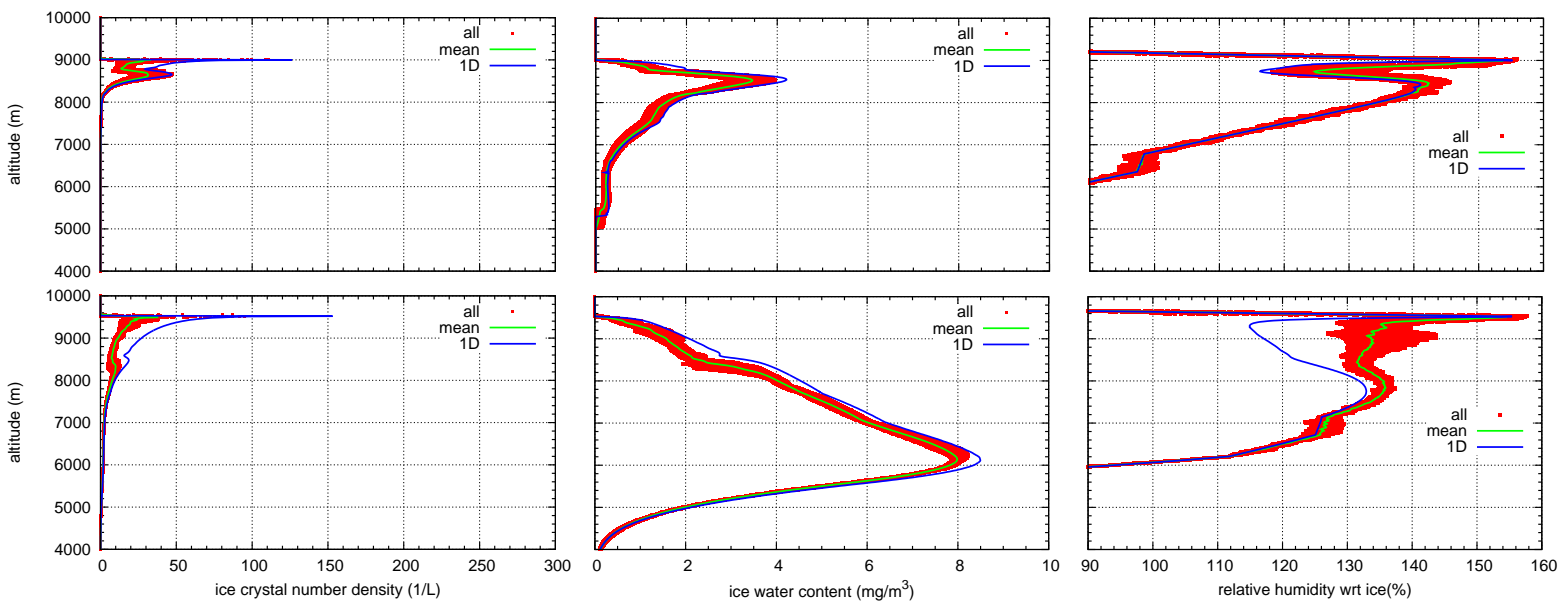

Fig. 14. Ice crystal number density (left), ice water content (middle) and relative humidity wrt ice (right) at $t=120 \mathrm{~min}$ (top panel) and at $t=240 \mathrm{~min}$ (bottom panel) for a constant updraught of $w=0.05 \mathrm{~m} \mathrm{~s}^{-1}$, additional temperature fluctuations and wind shear. The values at all grid points are indicated by the red dots, the mean value is represented by the green line and the blue line indicates the values of the corresponding 1-D simulation.

$w=0.08 \mathrm{~m} \mathrm{~s}^{-1}$ the lost 1-D structure, that is, the ice formation in the lower cloud levels, can be rediscovered, as Fig. 15 shows.

However, as the motions in the cloud are still random, the reappeared in-cloud nucleation events only occur at certain spots. An example of such an event is presented in Fig. 16 which shows the formation of a small nucleation region at the bottom of the cloud (in the altitude range $8300 \leq z \leq 8600 \mathrm{~m}$ ).

This nucleation event occurs in a strong upwind zone of a small eddy. In high time resolution (not shown) it can be observed that much more ice crystals form there than in the vicinity on the same level. Hence a strong gradient in ice crystal number density appears, while the horizontal variation of supersaturation is small. The crystals on this level grow thus with different rates, slowly in the spot of the nucleation burst, and faster elsewhere. This causes horizontal variations of terminal velocities, which is clearly seen in the time evolution shown in the figure. Wind shear shifts the falling crystals horizontally, eventually producing fall streaks. The time evolution of the 2-D structure (IWC $, N, w^{\prime}$ ) of this event is shown in Fig. 16.

In order to test whether such an event as just described occurs by chance or whether the dynamical effects mentioned before promote them we repeated the simulation with the same setup but with a different set of random numbers for the initialisation of the perturbations. In this case we got a similar in-cloud nucleation event, albeit a weaker one because the generating eddy was weaker. Hence it turned out that it is probably indeed the dynamical effects that promote such in-cloud nucleation bursts, and not simply random superposition of upward motions.

The strong depositional growth of the ice crystals in the nucleation burst leads to strong latent heat release
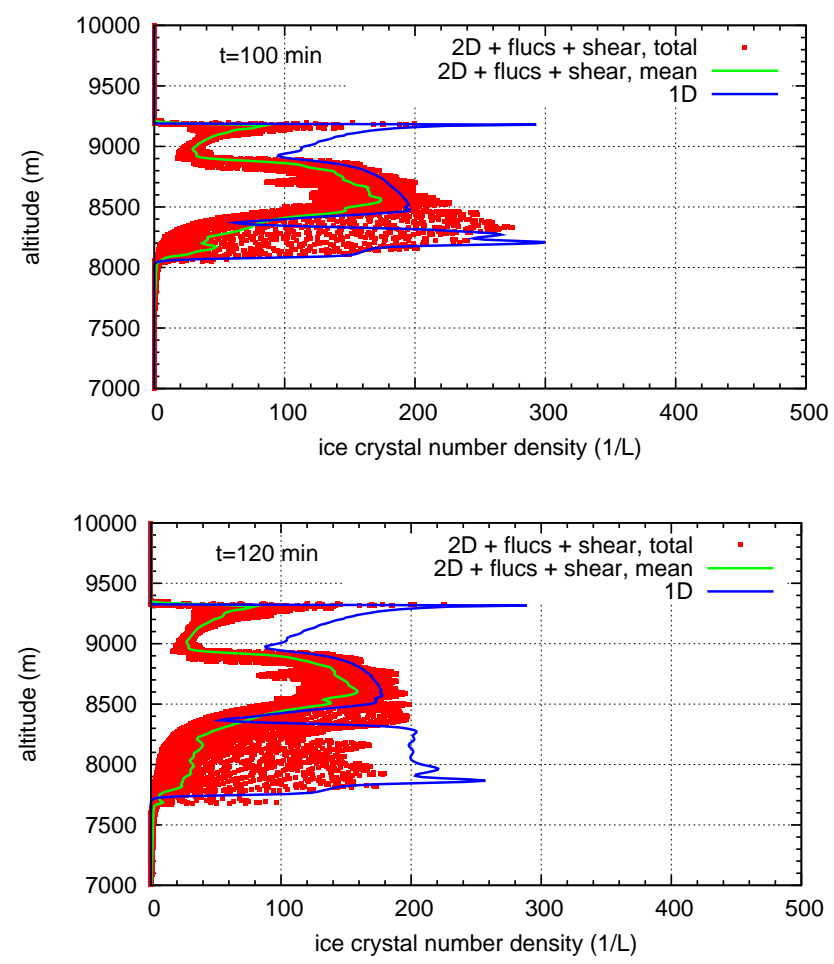

Fig. 15. Ice crystal number densities for a vertical updraught of $w=0.08 \mathrm{~m} \mathrm{~s}^{-1}$ with fluctuations and wind shear (red dots: all grid points, green line: mean value) and in the corresponding 1-D simulation (blue line) for $t=100 \mathrm{~min}$ (top) and $120 \mathrm{~min}$ (bottom), respectively. In contrast to the simulations including only temperature fluctuations (Fig. 11), here the incloud nucleation events at the cloud bottom occur; however, they are weaker than in the pure 1-D simulations. 


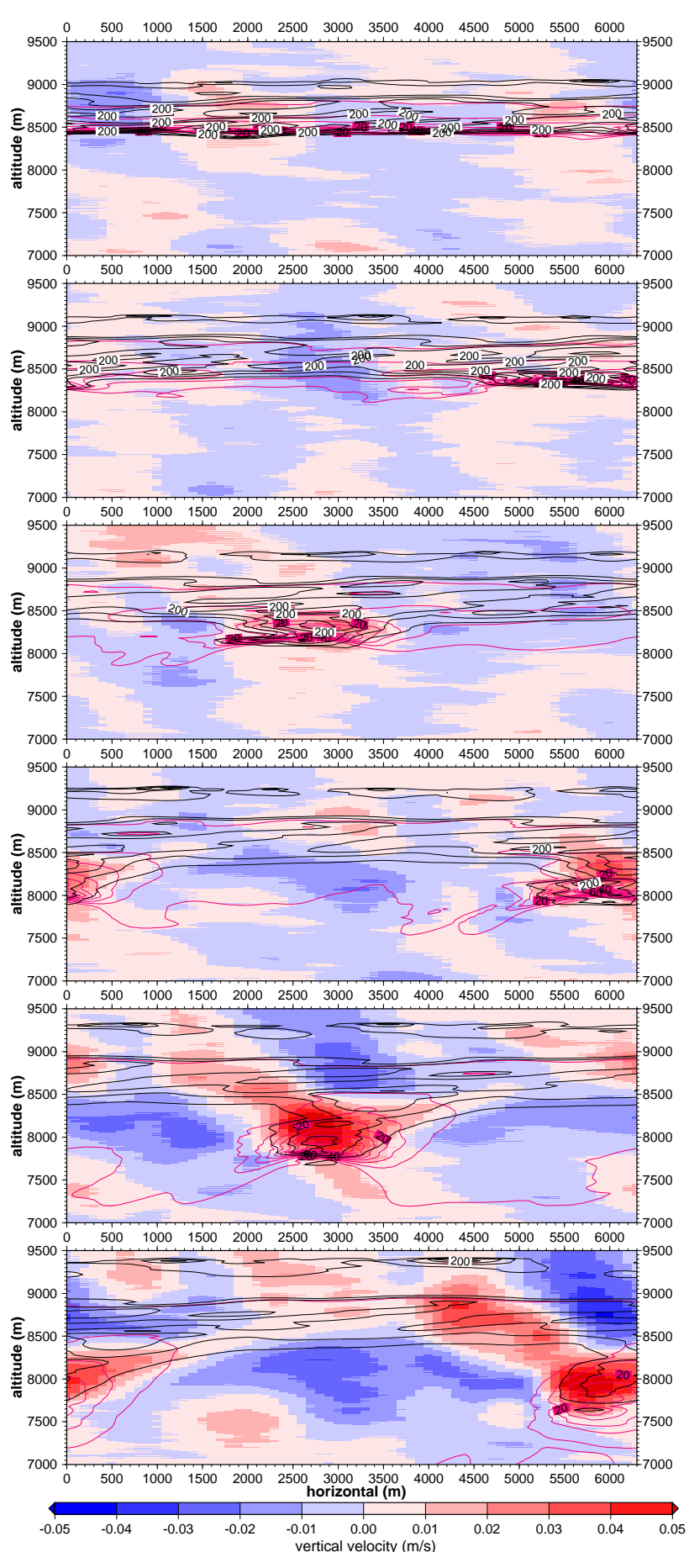

Fig. 16. Time evolution (from top to bottom: $t=$ $80 / 90 / 100 / 110 / 120 / 130 \mathrm{~min}$ ) of the ice water content (purple, in $\mathrm{mg} \mathrm{m}^{-3}, \Delta \mathrm{IWC}=5 \mathrm{mg} \mathrm{m}^{-3}$ ) and the ice crystal number density (black, in $\mathrm{L}^{-1} \Delta n_{c}=50 \mathrm{~L}^{-1}$ ) in case of a constant updraught of $w=0.08 \mathrm{~m} \mathrm{~s}^{-1}$ including initial temperature fluctuations and moderate wind shear. Vertical velocity perturbations $w^{\prime}$ are indicated by colours.

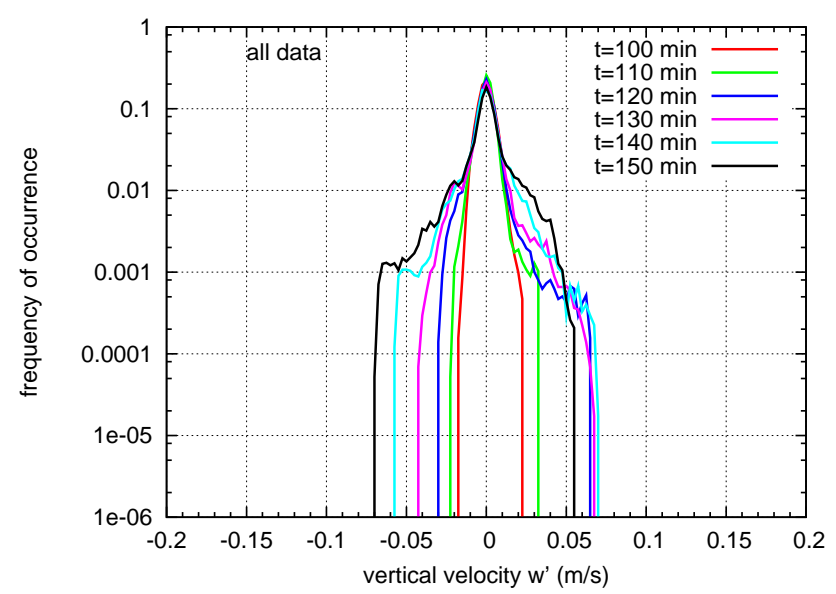

Fig. 17. Time evolution of the distribution of the vertical velocity perturbation $w^{\prime}$ in case of a constant large scale updraught of $\bar{w}=0.08 \mathrm{~m} \mathrm{~s}^{-1}$ including initial temperature fluctuations and a moderate wind shear $\left(d u / d z=10^{-3} \mathrm{~s}^{-1}\right)$.

approximately in their formation region. This heat in turn triggers additional updraughts with vertical velocities in the order of $0.05-0.1 \mathrm{~m} \mathrm{~s}^{-1}$ (cf. Fig. 16) which form the tails in the frequency distribution of $w^{\prime}$ that we show in Fig. 17 for the time range $100 \leq t \leq 150 \mathrm{~min}$ in $10 \mathrm{~min}$ intervals.

Comparing the results from the differing dynamical setups we can see that even small scale dynamics strongly affects the structure of a cirrus cloud whose formation was initially driven by large scale dynamics. This emphasises that simulating cirrus clouds is a multi-scale problem. The processes which are important for the formation and evolution of cirrus clouds act on different scales (e.g. cloud microphysics, small scale circulations, synoptic scale in our setup) and the evolving structure of cloud results from a superposition of processes acting on widely varying scales. Due to latent heat there is also a microphysics feedback on the local dynamics.

\subsection{RHi statistics}

A main feature of our simulations is the occurrence of (persistent) supersaturation inside the cirrus clouds. For another view on this phenomenon we have produced statistics of relative humidity in the simulations. For this we used the RHi at every grid point and at every $10 \mathrm{~min}$.

In Fig. 18 we compare the RHi-statistics for the 1-D and 2-D (with and without wind shear) simulations.

First we can note a cut-off in all distributions at around $160 \%$ relative humidity which is about the threshold for homogeneous nucleation at the cloud top temperatures. The finding of a cut-off is consistent with observations from the INCA campaign (Haag et al., 2003). Otherwise the figure shows that there is a tendency of all simulations to approach ice saturation after a while, as one expects. This tendency is strongest in the 1-D simulations and weakest in the 2-D 

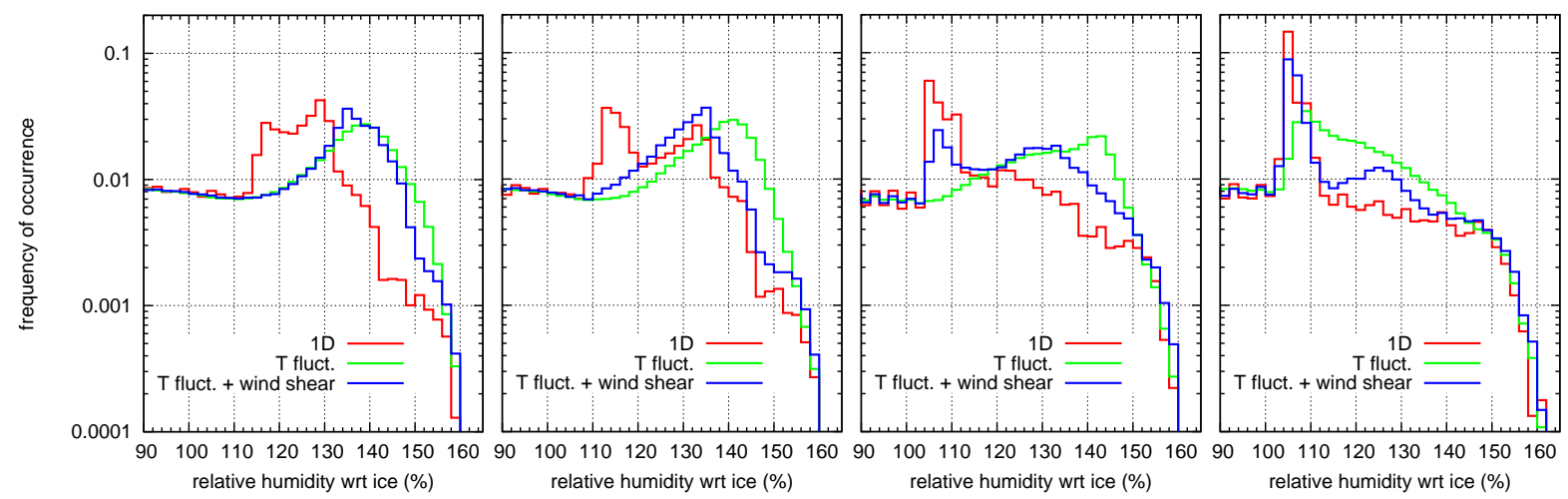

Fig. 18. Statistics of the relative humidity wrt ice for the simulations with different prescribed vertical velocities, from left to right: $w=0.05 \mathrm{~m} \mathrm{~s}^{-1}, w=0.06 \mathrm{~m} \mathrm{~s}^{-1}, w=0.08 \mathrm{~m} \mathrm{~s}^{-1}, w=0.1 \mathrm{~m} \mathrm{~s}^{-1}$, respectively. Here, all data from the whole simulation are collected, respectively. Red lines indicate the 1-D simulations, green lines denote 2-D simulations with temperature fluctuations and blue lines are 2-D simulations with temperature fluctuations and wind shear.

simulation without wind shear, that is, when the wind fluctuations have the strongest effect. Inclusion of wind shear enhances the tendency to approach ice saturation within the cloud, but the tendency is considerably weaker than in the 1-D case. These results show clearly that in-cloud supersaturation is not only an effect of microphysics, which is treated in the 1-D simulation as well as in the more realistic 2-D simulations. Cloud dynamics and persistent small-scale fluctuations especially in the wind field are at least as important for an explanation of this effect, if not more.

\section{Discussion}

Current concepts on cirrus formation imply that mesoscale velocity fluctuations explain the high ice number densities that are often observed (e.g. Hoyle et al., 2005; Haag and Kärcher, 2004). In contrast, here we find that wind fluctuations have the tendency to reduce crystal numbers. This seeming contradiction is easily explained once the difference between mesoscale fluctuations of vertical wind (gravity waves) and our small-scale fluctuations is recognised. The latter act on short time scales of seconds to minutes which only allows for small amplitudes in $w$-fluctuations. Gravity waves cause larger amplitudes in $w$ and act on longer time scales. Therefore, the largest vertical velocity fluctuations will dominate the nucleation process and produce the highest ice crystal number densities. The results may also contradict partially those of Kay et al. (2006) who estimated from box-model results that vertical velocity fluctuations affect the statistics of cloud optical thicknesses only when fluctuation time scales are shorter than fallout time scales, but longer than ice crystal growth rates. The "fluctuations" of Kay et al. (2006) are, however, waves whereas we use random perturbations of the wind field which act on shorter time scales than waves. Additionally, the box model simulations lack the spatial component, hence neither the horizontal nor the vertical transport and mixing of ice crystals with their subsequent effects on in-cloud supersaturation and nucleation can be modelled. These effects, namely (1) the weakening of ice formation in the horizontal neighbourhood of spots that just experienced a nucleation burst (because it was at the high end of the $w^{\prime}$ distribution) and (2) the sedimentation induced nucleation quenching (because a spot above was at the low end of the $w^{\prime}$ distribution) are important for structure formation of cirrus clouds, as we have seen.

From the foregoing analysis we have seen how important sedimentation is for the evolution of a cloud and its humidity field. In order to make the effect of sedimentation still clearer we repeated some of our 2-D simulations with $w=0.05 \mathrm{~m} \mathrm{~s}^{-1}$ using the same initialisation without/with fluctuations and wind shear, respectively, but we switched off the sedimentation. In this case a relatively short simulation time is sufficient, and we choose a simulation time of $84 \mathrm{~min}$ (i.e. a fifth of the original time). For comparison of the three simulations with each other and with the corresponding cases including sedimentation we present the statistics of the ice crystal number concentration, which we counted in all grid cells and at every 2 min (all taken together). The resulting distributions are shown in Fig. 19.

The 1-D run without sedimentation produces a sharp peak around $\sim 100 \mathrm{~L}^{-1}$, a value that we expect from the validation runs of Part 1a (temperature for nucleation events near $215 \mathrm{~K})$. The temperature and wind fluctuations in the 2-D run lead to strong broadening of the peak which is then rather a bulge than a peak. The most probable value of $n_{c}=N_{c} \rho$ is slightly shifted to a lower value. The mechanisms that cause these changes from the 1-D to the 2-D results have been explained above and need not be repeated. Inclusion of wind shear damps the fluctuations. Hence, there is still some broadening of the peak but less so than without the 


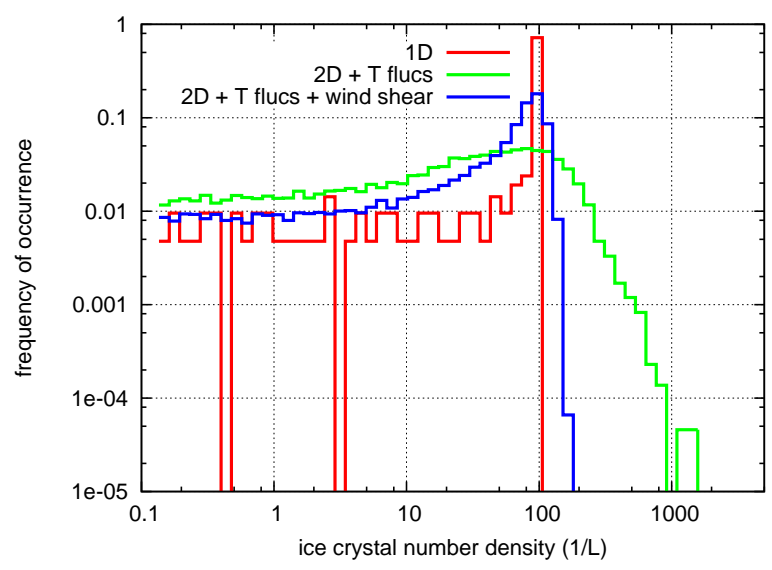

Fig. 19. Ice crystal number densities for three reference simulations (pure 1-D, temperature fluctuations, temperature fluctuations plus wind shear) without sedimentation. The whole model domain is lifted up with a constant vertical velocity of $w=0.05 \mathrm{~m} \mathrm{~s}^{-1}$. Again, all data for the whole simulation are collected, respectively. The frequency of occurrence of the ice crystal number densities is indicated by the coloured lines (red: pure 1-D, green: temperature fluctuation, blue: temperature fluctuations plus wind shear). The impact of the horizontal and vertical small scale motions, triggered by the temperature fluctuations is clearly visible.

shear. Since sedimentation was switched off, sedimentation induced quenching of nucleation cannot occur here. Hence the distributions display the effect of the horizontal mixing of the ice crystals alone. First, as expected, the high tail of the $w^{\prime}$ distribution leads to a high tail in the number density distributions, a larger one when wind shear is switched off and vice versa. But more interesting is the low tail, which displays the effect of the horizontal mixing. Both with and without wind shear there are much more grid boxes (and time steps) where low crystal number densities are found than in the case without fluctuations.

Now, we present the same kind of $n_{c}$-statistics for the simulations with sedimentation included. The values $n_{c}$ are counted every $10 \mathrm{~min}$. The result is displayed in Fig. 20.

We see clearly that the sedimentation process totally changes the distributions of $n_{c}$ with a strong shift of the frequencies of occurrence towards smaller ice crystal number densities. This is an important feature, which has to be taken into account for the interpretation of measurements: A priori, it is not clear, if the measured ice crystals were formed in situ or if they were sedimenting from formation layers above, changing the number density due to the sedimentation process. Sedimentation is a main process for structuring cirrus clouds in these simulations which were triggered by synoptic scale updraughts. For stronger updraughts (e.g. mesoscale waves or convective events) the picture might change because then much higher number concentrations of ice crystals are produced, with smaller and slower falling crystals. Under such conditions, when the sedimentation time scale exceeds

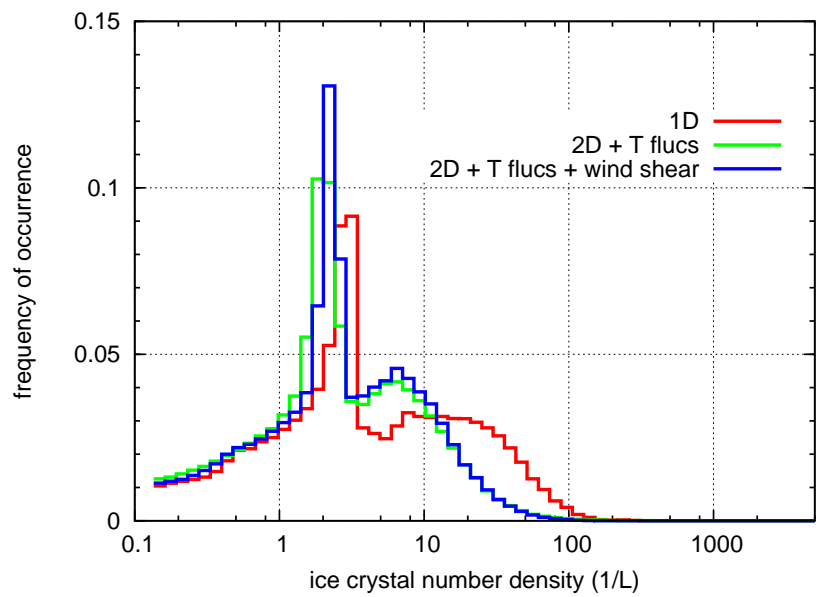

Fig. 20. Ice crystal number densities for three reference simulations (pure 1-D, temperature fluctuations, temperature fluctuations plus wind shear) with sedimentation. The whole model domain is lifted up with a constant vertical velocity of $w=0.05 \mathrm{~m} \mathrm{~s}^{-1}$. Again, all data for the whole simulation are collected, respectively. The frequency of occurrence of the ice crystal number densities is indicated by the coloured lines (red: pure 1-D, green: temperature fluctuation, blue: temperature fluctuations plus wind shear). In comparison with Fig. 19, sedimentation influences already the pure 1-D case dispersing the ice crystal number density over the whole cloud which leads to a shift in the frequency of occurrence towards smaller densities.

the growth time scale, sedimentation can be less important than in the cases presented here.

Box model simulations usually cannot treat sedimentation (recent developments excepted): Although the ice flux out of the lower lid of the box can easily be computed, the ice flux into the box at the upper lid cannot because this requires knowledge of the ice mass and number concentration above (i.e. outside) the box, which is not given. From this point of view it seems that box model studies of clouds should be constrained to the formation and early evolution phase or other conditions when sedimentation is still unimportant (e.g. when only small ice crystals are present), notwithstanding applications like those of Kay et al. (2006).

Many of the figures shown in this paper show profiles of relative humidity with double peaks. These are a consequence of the ongoing cooling of the ISSR/cloud layer interacting with the sedimentation of the ice crystals. The upper peak is always at the ISSR/cloud top. Ice crystals form there, grow and start to fall. Then supersaturation increases again (due to cooling) because the sink for excess vapour has fallen away. On reaching the threshold for homogeneous nucleation again new crystals form, and so on. The mid-cloud peaks of RHi are caused by the ongoing cooling in combination with sedimentation, as well. However, crystals sedimenting from above into the mid-cloud level make the timing and profile shaping of these peaks more complicated than that of the peaks at cloud top. 
We found that the qualitative structure of cirrus clouds driven by synoptic upward motions can be represented quite well using a 1-D approach. However, small scale fluctuations can affect the cloud structure substantially. There are some kind of "off equilibrium" situations (because of the non-linear processes involved, in particular nucleation) when small causes can lead to big effects, that is, change the cloud evolution completely, leading to totally different structure of the cloud. In these cases a 2-D approach using temperature fluctuations is needed to get deeper insight into the dominant processes that act in structuring the cirrus clouds.

\section{Conclusions}

We have used the newly developed and validated microphysics scheme (Spichtinger and Gierens, 2009) implemented into the the anelastic, non-hydrostatic model EULAG (Smolarkiewicz and Margolin, 1997) to investigate the sensitivity of cirrus cloud evolution to variations in largescale and small-scale dynamics. As a test object we reused the artic cirrostratus that we already used for model validation in Part 1a. In the sensitivity studies we varied the overall updraught velocity in the synoptic range $w=0.05 / 0.06 / 0.08 / 0.1 \mathrm{~m} \mathrm{~s}^{-1}$. In additional simulations we superposed inital temperature fluctuations leading to smallscale eddies and furthermore we included a moderate wind shear.

These studies led to the following conclusions:

- Sedimentation is of utmost importance in the evolution of the cloud structure and the in-cloud humidity field; sedimenting ice crystals can quench in-cloud nucleation;

- The almost binary behaviour of the nucleation process (on or off), that is, the existence of relatively sharp supersaturation thresholds (or supercooling thresholds) can lead to dramatic changes of cloud structures as a response to weak or moderate changes in the overall situation (e.g. uplift speed) and to the interaction between the local eddies and the large-scale wind shear;

- Persistent in-cloud supersaturation is found in all our simulations. It is not only an effect of microphysics but at least as important is cloud dynamics on both the large and the small scale;

- Cirrus clouds are good examples for a multi-scale problem. Microphysical processes act on the smallest scales, but they are driven by the external meso- and large-scale wind fields. Cloud-internal dynamics and the smallscale fluctuations modify the process rates locally, and are in turn affected by latent heat exchanges with the cloudy air. The superposition of these processes and the lasting shifting in their relative importance is crucially responsible for the structural evolution of the cirrus cloud.

In future applications the model will be used for investigating the effects of the competition of different nucleation mechanisms (Spichtinger and Gierens, 2008) and for investigations of the impact of orographic gravitiy waves on the formation and evolution of cirrus clouds (as in Spichtinger and Dörnbrack, 2006).

Acknowledgements. We are grateful to Piotr K. Smolarkiewicz for sharing his model and Andreas Dörnbrack for help in using the model. Both of these and Marcia Baker, Bernd Kärcher, Ulrike Lohmann, Thomas Peter, Olaf Stetzer and Marian deReus stimulated the work with many fruitful discussions. This study contributes to the DFG (German research foundation) project "Dünner Zirrus" (GI 333/1-1) and to the DLR/HGF-project "Particles and Cirrus Clouds" (PAZI-2). The numerical simulations were carried out at the European Centre for Medium-Range Weather Forecasts (special project "Ice supersaturation and cirrus clouds").

Edited by: P. Haynes

\section{References}

Bacmeister, J., Eckermann, S., Tsias, A., Carslaw, K., and Peter, T.: Mesoscale temperature fluctuations induced by a spectrum of gravity waves: A comparison of parameterizations and their impact on stratospheric microphysics, J. Atmos. Sci., 56, 19131924, 1999.

Birner, T.: Fine-scale structure of the extratropical tropopause region, J. Geophys. Res., 111, D04104, doi:10.1029/2005JD006301, 2006.

Comstock, J., Ackerman, T. P., Turner, D. D.: Evidence of high ice supersaturation in cirrus clouds using ARM Raman lidar measurements. Geophys. Res. Lett., 31, L11106, doi:10.1029/2004GL019705, 2004.

DeMott, P. J., Rogers, D. C., and Kreidenweis, S. M.: The susceptibility of ice formation in upper tropospheric clouds to insoluble aerosol components, J. Geophys. Res., 102, 19575-19584, 1997.

Dürbeck, T. and Gerz, T.: Dispersion of aircraft exhausts in the free atmosphere, J. Geophys. Res., 101, D20, 26007-26015, 1996.

Emanuel, K.: Atmospheric convection, Oxford University Press, 580 pp., 1994.

Gerz, T.: Coherent structures in stratified turbulent shear flows deduced from direct simulations, in: Turbulence and Coherent Structures, edited by: Métais, O. and Lesieur, M., Grenoble, 1821 September 1989, Kluwer, Dordrecht, Netherlands, 449-468, 1991.

Gierens, K.: On the transition between heterogeneous and homogeneous freezing, Atmos. Chem. Phys., 3, 437-446, 2003, http://www.atmos-chem-phys.net/3/437/2003/.

Gierens, K., Kohlhepp, R., Dotzek, N., and Smit, H. G.: Instantaneous fluctuations of temperature and moisture in the upper troposphere and tropopause region. Part 1: Probability densities and their variability, Meteorol. Z., 16, 221-231, 2007.

Haag, W. and Kärcher, B., Ström, J., Minikin, A., Lohmann, U., Ovarlez, J., and Stohl, A.: Freezing thresholds and cirrus cloud 
formation mechanisms inferred from in situ measurements of relative humidity, Atmos. Chem. Phys., 3, 1791-1806, 2003, http://www.atmos-chem-phys.net/3/1791/2003/.

Haag, W. and Kärcher, B.: The impact of aerosols and gravity waves on cirrus clouds at midlatitudes, J. Geophys. Res., 109, D12202, doi:10.1029/2004JD00457, 2004.

Heymsfield, A. J., and Sabin, R. M. : Cirrus crystal nucleation by homogeneous freezing of solution droplets, J. Atmos. Sci., 46, 2252-2264, 1989.

Hoyle, C., Luo, B., and Peter, T.: The origin of high ice crystal number densities in cirrus clouds, J. Atmos. Sci., 62, 2568-2579, 2005.

Kärcher, B.: Supersaturation, dehydration, and denitrification in Arctic cirrus, Atmos. Chem. Phys., 5, 1757-1772, 2005, http://www.atmos-chem-phys.net/5/1757/2005/.

Kärcher, B. and Lohmann, U.: A Parameterization of cirrus cloud formation: Homogeneous freezing of supercooled aerosols, J. Geophys. Res., 107(D2), 4010, doi:10.1029/2001JD000470, 2002.

Kärcher, B. and J. Ström: The roles of dynamical variability and aerosols in cirrus cloud formation, Atmos. Chem. Phys., 3, 823838,2003 , http://www.atmos-chem-phys.net/3/823/2003/.

Kärcher, B., Hendricks, J., and Lohmann, U.: Physicallybased parameterization of cirrus cloud formation for use in global atmospheric models, J. Geophys. Res., 111, D01205, doi:10.1029/2005JD006219, 2006.

Kay, J. E., Baker, M., and Hegg, D.: Microphysical and dynamical controls on cloud optical depth distributions, J. Geophys. Res., 111, D24205, doi:10.1029/2005JD006916, 2006.

Koop, T.: Homogeneous ice nucleation in water and aqueous solutions, Z. Phys. Chem., 218, 1231-1258, 2004.

Krämer, M., Schiller, C., Afchine, A., Bauer, R., Gensch, I., Mangold, A., Schlicht, S., Spelten, N., Sitnikov, N., Borrmann, S., de Reus, M., Spichtinger, P.: Ice supersaturations and cirrus cloud crystal numbers, Atmos. Chem. Phys. Discuss., 8, 21089-21128, 2008 , http://www.atmos-chem-phys-discuss.net/8/21089/2008/.

Lee, S.-H., Wilson, J. C., Baumgardner, D., Herman, R. L., Weinstock, E. M., LaFleur, B. G., Kok, G., Anderson, B., Lawson, P., Baker, B., Strawa, A., Pittman, J. V., Reeves, J. M., and Bui, T. P.: New particle formation observed in the tropical/subtropical cirrus clouds, J. Geophys. Res., 109, D20209, doi:10.1029/2004JD005033, 2004.
Lin, R.-F., Starr, D., Reichardt, J., and DeMott, P.: Nucleation in synoptically forced cirrostratus, J. Geophys. Res., 110, D08208, doi:10.1029/2004JD005362, 2005.

Liu, X., Penner, J. E., Ghan, S. J., and Wang, M.: Inclusion of ice microphysics in the NCAR Community Atmospheric Model Version 3 (CAM3), J. Climate, 20, 4526-4547, 2007.

Ovarlez, J., Gayet, J.-F., Gierens, K., Ström, J., Ovarlez, H., Auriol, F., Busen, R., and Schumann, U.: Water vapor measurements inside cirrus clouds in northern and southern hemispheres during INCA, Geophys. Res. Lett., 29, 1813, doi:10.1029/2001GL014440, 2002.

Peter T., Marcolli C., Spichtinger P., Corti, T., Baker M. B., and Koop, T.: When dry air is too humid, Science, 314 (5804), 13991400, 2006.

Peter, T., Krämer, M., and Möhler, O.: Upper Tropospheric Humidity, SPARC/WCRP Newsletter 30, 9-15, 2008.

Ren, C. and MacKenzie, R.: Cirrus parametrization and the role of ice nuclei, Q. J. Roy. Meteror. Soc., 131, 1585-1605, 2005.

Sassen, K. and Dodd, G. C.: Homogeneous nucleation rate for highly supercooled cirrus cloud droplets, J. Atmos. Sci., 45, 1357-1369, 1988.

Smolarkiewicz, P. and Margolin, L.: On forward-in-time differencing for fluids: an Eulerian/Semi-Lagrangian non-hydrostatic model for stratified flows, Atmos.-Ocean., 35, 127-152, 1997.

Spichtinger P. and Dörnbrack, A.: Microphysical modeling of orographic cirrus clouds, Proceedings of the 12th AMS Conference on Cloud Physics, Madison, USA, 2006.

Spichtinger, P. and Gierens, K. M.: Modelling of cirrus clouds Part 2: Competition of different nucleation mechanisms, Atmos. Chem. Phys. Discuss., 8, 9061-9098, 2008, http://www.atmos-chem-phys-discuss.net/8/9061/2008/.

Spichtinger, P. and Gierens, K. M.: Modelling of cirrus clouds Part 1a: Model description and validation, Atmos. Chem. Phys., 9, 685-706, 2009, http://www.atmos-chem-phys.net/9/685/2009/. 